\title{
Testing novel multicomposite materials for electromethanogenesis
}

\author{
Giorgia Ghiara ${ }^{1}$, Stefano Trasatti $^{1}$, Andrea Goglio $^{2}$, Pierangela Cristiani $^{3 *}$ \\ ${ }^{1}$ Università degli Studi di Milano, Department of Environmental Sciences and Policy, Milano, Italy \\ ${ }^{2}$ Università degli Studi di Milano, Department of Agricuture and Environmental Sciences, Milano, Italy \\ ${ }^{3}$ Ricerca sul Sistema Energetico - RSE S.p.A., 20134 Milano, Italy
}

\begin{abstract}
Electromethanogenesis is an innovative technology that uses a microbial electrochemical system to produce methane from $\mathrm{CO}_{2}$, in a power-to-gas (BEP2G) concept. The results of experimental tests of new and cost-effective carbonaceous materials for electrode are presented here. The study aims at optimizing electromethanogenesis processes at laboratory level in mesothermic condition. As part of the experiments, hydrogenotrophic microorganisms (Family Metanobacteriaceae of Archaea domains) were selected from a mixed consortium taken from a biogas digestate and inoculated in double-chamber bioelectrochemical systems. The maximum amount of methane produced was $0.3-0.8 \mathrm{~mol} / \mathrm{m}^{2} \mathrm{~g}$ (normalized to the cathode area) with carbon cloth electrodes. Aiming at improving the methane productivity, innovative materials for the electrodes were now studied, creating porous high-surface composites, and studying nitrogen carbons doped with $\mathrm{Cu}$ and hydroxyapatite (Multicomposite $\mathrm{Cu} @ / \mathrm{HAP} / \mathrm{C}$ ), as chemical catalysts for $\mathrm{CO}_{2}$ reduction $(\mathrm{CO} 2 \mathrm{RR})$. The description of the procedure for the Multicomposite $\mathrm{Cu} @ / \mathrm{HAP} / \mathrm{C}$ production is reported in detail.
\end{abstract}

\section{Introduction}

Electromethanogenesis also called bioelectrochemical power-to-gas (BEP2G) is an innovative technology for storing renewable electricity in the form of methane, alternative to both biochemical methanogenesis and thermochemical methanation (Sabatier process) [1,2]. The process is supported by specific microorganisms selected FROM biogas plants or from natural anaerobic environments [3]. In BEP2G carbon dioxide $\left(\mathrm{CO}_{2}\right)$ and electrical energy are converted directly into methane $\left(\mathrm{CH}_{4}\right)$ on electrodes colonized by methanogenic microorganisms of the Archea domain [4,5]. In general, the mechanisms for the $\mathrm{CH}_{4}$ production, in absence of electricity are different and depend on the metabolic pathways ascribed to the selected species. Two main pathways for methanogenesis are known: i) hydrogenotrophic; ii) acetoclastic. These metabolic processes start from two main types of molecules, respectively: i) carbonate ion; ii) acetate ion (or methanol). The values of Gibbs free energy at standard conditions $\left(25^{\circ} \mathrm{C}\right.$ and $\left.\mathrm{pH} 7\right)$ [6] differ by the nature of the substrate and the energy source used to produce $\mathrm{CH}_{4}$ $[7,8]$. Among these, the most widespread and most metabolically efficient process for energy generation is the hydrogenotrophic one $[9,10]$

Using electricity, methanogenesis can be achieved using only carbon dioxide and bicarbonate as the only source of carbon and, it can be coupled to both the abiotic oxidation of water and the abiotic, or microbial, oxidation of organic molecules [11-13]. According to this set-up, microorganisms catalyze the reduction of carbon dioxide introduced into the cathode chamber to methane on a polarized cathode, which donates electrons following reaction (1):

$$
\mathrm{CO}_{2}+8 \mathrm{H}^{+}+8 e-=\mathrm{CH}_{4}+2 \mathrm{H}_{2} \mathrm{O}
$$

Furthermore, microbial electromethanogenesis can be effectively combined with the conventional anaerobic digestion (AD) process using $\mathrm{CO}_{2}$-rich gases produced by biogas plants (methane up-grading) or using $\mathrm{CO}_{2}$-rich industrial waste gases. However, it is a relatively recent technology, still mainly experimented at a laboratory level $[1,2]$.

Lately, novel approaches have been proposed to solve technological problems and to make it a energy storage system more economically and industrially competitive $[1,2]$. Research on the optimization of the design and configuration of the bioreactors were carried out to reproduce the systems on a larger scale [2]. They manly focused on the chamber set-up (i.e., single, or dual chamber), the applied cathode potential $(\sim 1 \mathrm{~V})$, the choice of microorganisms, the cathode and/or anode feeding, the $\mathrm{pH}$, etc... [14-17]. An alternative, relevant, approach is the study of different materials for the cathode. Electrodes must give large surfaces to maximize the interaction with microorganisms minimizing charge transfer resistance and diffusive mass transport [15]. Carbon-based materials are particularly suitable for electrochemical systems, especially biochar, which aroused great interest for such

\footnotetext{
${ }^{*}$ Corresponding author: Pierangela.Cristiani@rse-web.it
} 
application $[18,19]$. In this study the authors present the first results of the use of an innovative composite carbon based electrocatalysts (e.g., biogenic carbon) functionalized with copper nanoparticles $(\mathrm{Cu} @)$ and hydroxyapatite (HAP) as a cathode material where reduce $\mathrm{CO}_{2}\left(\mathrm{CO}_{2} \mathrm{RR}\right)$ to $\mathrm{CH}_{4}$. The choice of a carbon of biological origin (biochar) as a support for both $\mathrm{Cu} @$ and HAP was made according to the necessity to have suitable performances, in terms of porosity, conductivity, biocompatibility, mechanical resistance and resilience $[20,21]$. Furthermore, $\mathrm{Cu} @$ is an active phase that directly promotes a further reduction of $\mathrm{CO}_{2}$ (transfers $>2 \mathrm{e}^{-}$) to a wide range of so-called higher order products $\left(\right.$ as $\mathrm{CH}_{4}, \mathrm{C}_{2}$ or $\mathrm{C}_{3}$ ), while HAP enhances the selectivity towards $\mathrm{CH}_{4}$ $[22,23]$. The preparation of the electrode material $(\mathrm{Cu} @ / \mathrm{HAP} / \mathrm{C})$ is an important part of the experiment, and an innovative multi-phase protocol is introduced here.

\section{Materials and methods}

\subsection{Biochar production}

To obtain an electrically conductive material, giant cane (Arundo Donax. L., 1753) was employed. The canes were positioned in a quartz tube inside a horizontal furnace (Carbolite) and pyrolyzed accordingly. The pyrolysis procedure of the material was carried out according to the following protocol: 2 hours at $25{ }^{\circ} \mathrm{C}$, slow heating (10 ${ }^{\circ} \mathrm{C} / \mathrm{min}$ ) up to $900{ }^{\circ} \mathrm{C}, 1 \mathrm{~h}$ held at $900^{\circ} \mathrm{C}$ and cooling down to $25{ }^{\circ} \mathrm{C}$ according to [24]. During all the pyrolysis treatment, nitrogen flowed constantly at $1 \mathrm{NL} / \mathrm{h}$. This type of procedure allows high temperatures to be reached in a short time and maximum treatment efficiency, without any heat loss.

\subsection{Multicomposite Cu@/HAP/C production}

The composite produced followed a multi-step protocol that involved the use of copper nanoparticles (SigmaAldrich, CAS 7440508, ø $=25 \mathrm{~nm}$ ) and hydroxyapatite (produced at the University of Milan according to a procedure described elsewhere [25]). Firstly, biochar was pulverized using an agate mortar. The powder was subsequently used as a support for copper nanoparticles ( $\mathrm{Cu} @$ ) and hydroxyapatite (HAP). Approximately. $95 \mathrm{mg}$ of biochar was dispersed in ca. 40 $\mathrm{ml}$ of isopropyl alcohol (IPA) (Figure 1a).
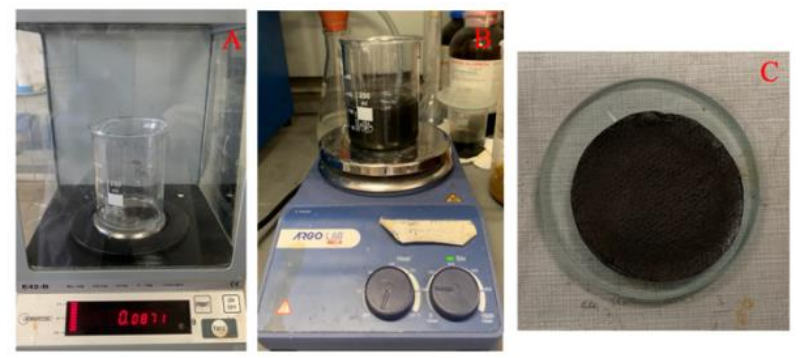

Fig. 1. Protocol to produce the multicomposite $\mathrm{Cu} @ / \mathrm{HAP} / \mathrm{C}$.
The $\mathrm{pH}$ of the suspension was adjusted to 10 by adding an aqueous solution of $0.1 \mathrm{M} \mathrm{KOH}$. Similarly, approx. $5 \mathrm{mg}$ of commercial $\mathrm{Cu}$ NP were dispersed in ca. $40 \mathrm{~mL}$ of IPA, adjusting the $\mathrm{pH}$ as indicated for the biochar suspension. Both mixtures were placed on ultrasound for 30 minutes to obtain an optimal suspension. Then, the $\mathrm{Cu}$ NP suspension was added one shot to the biochar suspension. The resulting mixture was stirred at room temperature for 48 hours (Figure $1 b$ ).

After the immobilization step, the powder was vacuum filtered on a $0.45 \mathrm{~m}$ Nylon membrane, washed with MilliQ water and dried at $110^{\circ} \mathrm{C}$ for 45 minutes. The sample obtained was labeled $\mathrm{Cu@/C.} \mathrm{Approximately.100}$ mg of $\mathrm{Cu} @ / \mathrm{C}$ were suspended in ca. $90 \mathrm{ml}$ of MilliQ water. The $\mathrm{pH}$ of the suspension was brought to 7 by adding a $0.1 \mathrm{M}$ aqueous solution of $\mathrm{KOH}$. Similarly, ca. 7 $\mathrm{mg}$ of HAP were dispersed in ca. $20 \mathrm{~mL}$ of MilliQ water, adjusting the $\mathrm{pH}$ of the suspension to 7 by adding a $0.1 \mathrm{M}$ $\mathrm{KOH}$ solution. Both mixtures were sonicated for 45 minutes. Then, the HAP suspension was added to the $\mathrm{Cu} @ / \mathrm{C}$ suspension in one shot; the resulting mixture was stirred for $72 \mathrm{~h}$ at room temperature. Finally, the powder was vacuum filtered on a $0.45 \mathrm{~m}$ Nylon membrane, washed with MilliQ water and dried at $110^{\circ} \mathrm{C}$ for 3 hours (Figure 1c). This sample obtained was labeled $\mathrm{Cu} @ / \mathrm{HAP} / \mathrm{C}$ and the desired composition is presumed to be 5 wt. $\% \mathrm{Cu}$ and 5 wt. \% HAP.

\subsection{Set-up of the bioelectrochemical cells}

The dual chamber system was made with borosilicate (Pyrex) bottles. The anode and the cathode chambers, both characterized by a volume of $200 \mathrm{~mL}$, were separated by a proton exchange membrane (PEM NAFION 417) (working surface: $7.0 \mathrm{~cm}^{2}$ ). $\mathrm{CO}_{2}$ was fluxed at the cathode at the beginning of the experiment for 10 minutes. The catholyte solution consisted of the inoculum retrieved from an online biogas plant and stored at University of Milan, Bicocca. The inoculum was supplied with $2.54 \mathrm{~g} / \mathrm{L}$ $\mathrm{KH}_{2} \mathrm{PO}_{4}, 11.7 \mathrm{~g} / \mathrm{L} \mathrm{Na} \mathrm{HPO}_{4} * 12 \mathrm{H}_{2} \mathrm{O}, 0.53 \mathrm{~g} / \mathrm{L} \mathrm{NH} 4 \mathrm{Cl}$, $0.1 \mathrm{~g} / \mathrm{L} \mathrm{Na} 2 \mathrm{SO} 4,5.0 \mathrm{~g} / \mathrm{L} \mathrm{NaHCO}_{3}$, and vitamins. The anolyte consisted of a solution of $0.2 \mathrm{M} \mathrm{Na} \mathrm{NO}_{4}$. The cathode was made of different materials and operated to verify, in comparison, the methane production.

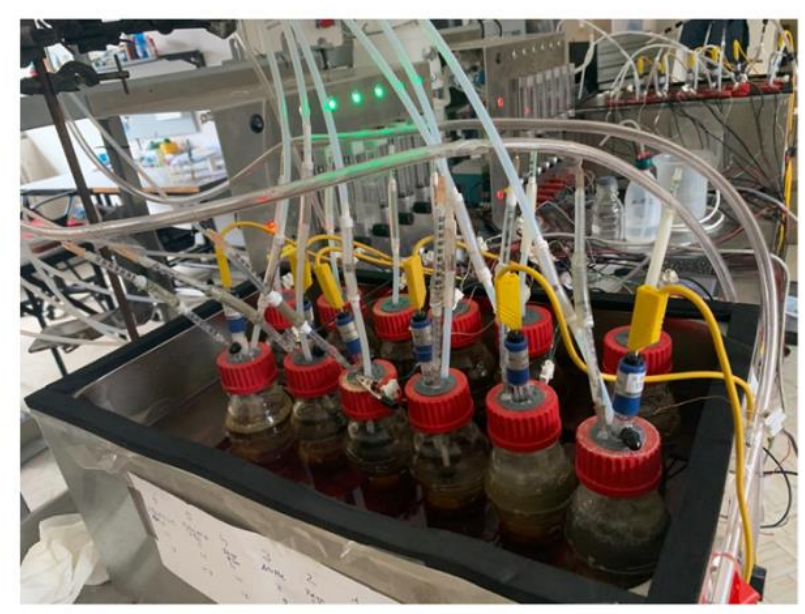


Fig. 2. Set-up of the bioelectrochemical cell.

Three materials were used for the cathode: i) carbon cloth (CC); biochar (C); multicomposite $\mathrm{Cu@/HAP/C.} \mathrm{All}$ electrodes had a comparable surface area of $100 \mathrm{~cm}^{2}$. The anode was a Ti-mesh of a suitable area of $36 \mathrm{~cm}^{2}$. Both anodic and cathodic collector wires were connected to a potentiostat (Amel S.r.l. Milan, Italy) that acted as a power supply. The recording of the potential imposed between the cell and the generated current was performed with an Agilent 4930 A data-logger. A reference electrode $\mathrm{Ag} / \mathrm{AgCl} 3 \mathrm{M}$ was inserted in each cathodic compartment. The potential imposed on the cathode during the test was $-1.2 \mathrm{~V}$ vs the reference electrode, corresponding to approximately $-1 \mathrm{~V}$ vs SHE (Standard Hydrogen Electrode). The duration of the experiments was 6 days and was replicated twice.

\subsection{Analytical methods}

To verify the morphology (i.e., pore size) of the pyrolyzed biochar and to characterize the multicomposite produced a Scanning Electron Microscopy analysis (SEM) coupled with Energy dispersive X-Ray measurements (EDS) was carried out at the Department of Earth Sciences of the University of Milan. The analyses were conducted at different magnifications and with an acceleration voltage of $20 \mathrm{KeV}$ using secondary electrons (SE) detector.

The composition of biogas $\left(\mathrm{CH}_{4}, \mathrm{H}_{2}\right.$, and $\left.\mathrm{CO}_{2}\right)$ was analyzed using a gas chromatograph (GC) at the Department of Agriculture of the University of Milan. The sample for the GC was taken from the headspace of the bioreactor cathode chamber with flex-foil bags ( 1 and 5L) connected to the gas escape system. Numerous gas samplings were carried out on a weekly basis, lasting about 60 minutes. The quantity of $\mathrm{CH}_{4}$ produced was expressed as a percentage of gas found. Furthermore, the $\mathrm{pH}$ was monitored on a three-day-basis.

\section{Results}

\subsection{Biochar production}

Firstly, A. Donax samples were weighted before and after pyrolysis to verify the success of the procedure. Figure 3 shows a sample before and after the treatment.

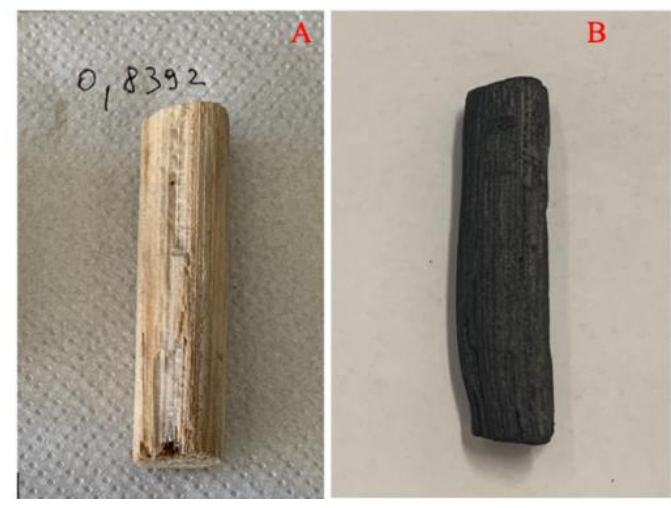

Fig. 3. Example of: A) pre pyrolyzed sample; B) pyrolyzed sample

Generally, a weight loss corresponding to approximately $75 \%$ of the initial weight was highlighted for all samples, consistent with the decomposition of the material in the absence of oxygen. During this process, the lignocellulosic components such as cellulose $\left(\mathrm{C}_{6} \mathrm{H}_{10} \mathrm{O}_{5}\right)$ $\mathrm{n}$-hemicellulose and lignin undergo depolymerization reactions, fragmentation, and cross-linking [26]. It is in fact known from the literature that pyrolysis increases the porosity of the material and the surface area even by several orders of magnitude [26]. Porosity is formed because of the loss of water during the treatment. To define the size of the pores we proceeded with a SEM analysis. As can be seen from Figure 4, the material after pyrolysis maintained the same mechanical structure and highlighted an increasing number of pores on the surface, confirming the success of the treatment.

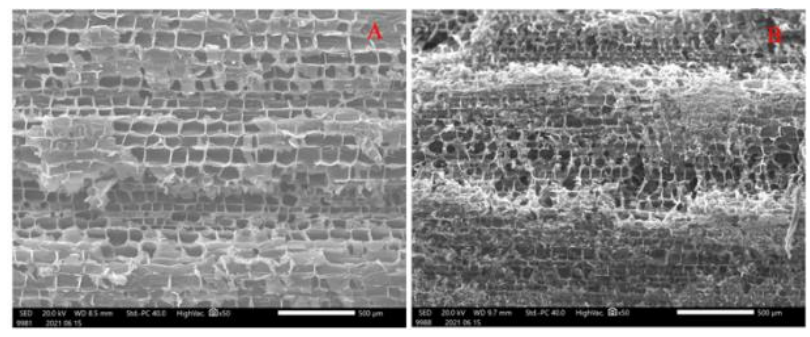

Fig. 4. SEM-SE micrographs of: A) pre pyrolyzed sample; B) pyrolyzed sample

Generally, three types of pores can be distinguished followed by various applications of biochar: i) micropores $(<2 \mathrm{~nm})$; ii) mesopores $(2-50 \mathrm{~nm})$; ii) macropores $(>50$ $\mathrm{nm})$. As displayed by the figure the material is composed of macropores, with average dimensions around $50 \pm 10$ $\mu \mathrm{m}$. This is a promising result for its use as an electrode as the presence of macropores favors: i) the diffusion of gases $\left(\mathrm{CO}_{2}\right.$ and $\left.\mathrm{H}_{2}\right)$ inside the material, also allowing for a good wettability by the $\mathrm{H}_{2} \mathrm{O}$; ii) the extracellular transfer of electrons by microbes that catalyze the direct production reaction of methane. 


\subsection{Multicomposite Cu@/HAP/C production}

Figure 5 displays the qualitative results obtained by the EDS analysis on the powder.

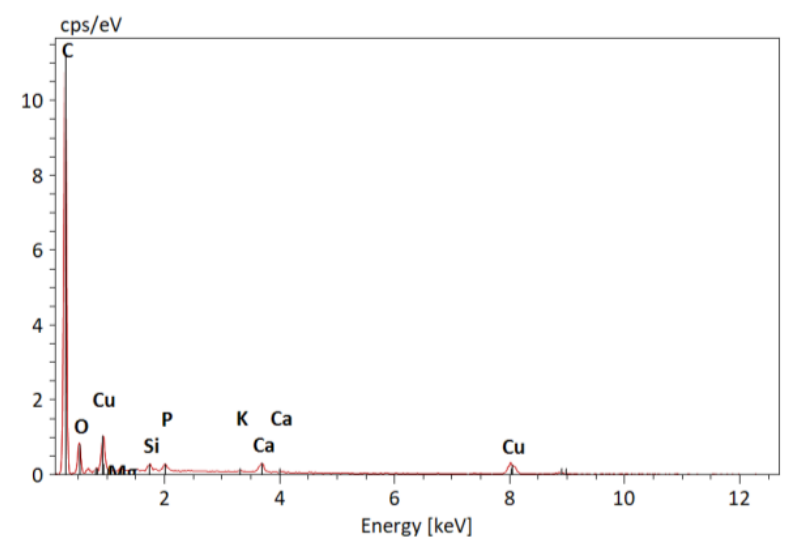

Fig. 5. EDS average spectrum of the $\mathrm{Cu} @ / \mathrm{HAP} / \mathrm{C}$ multicomposite.

As expected, the spectrum indicated a high percentage of $\mathrm{C}$ on the surface, attributed to the biochar. However, the signals of $\mathrm{Cu}, \mathrm{Ca}, \mathrm{O}$ and $\mathrm{P}$ are detected, which implies the success of the methodology. In fact, hydroxyapatites bear generally the following stoichiometry: $\mathrm{Ca}_{10}\left(\mathrm{PO}_{4}\right)_{6}(\mathrm{OH})_{2}$. However, it was not possible to further quantify the overall percentage of the single components due to quantification limits connected to the massive presence of carbon. Further investigation will thus be dedicated to the study of the distribution of the $\mathrm{Cu} @$ and HAP on the biochar and exact composition of this multicomposite material.

\subsection{Bioelectrochemical cells}

\subsubsection{Current output}

Figure 6 shows the trend of the cell current $\left(I_{\text {cell }}\right)$ circulating for $140 \mathrm{~h}$, considering the average. Red and blue arrows indicate gas and $\mathrm{pH}$ sampling, respectively. It should be noticed that the $\mathrm{CO}_{2}$ dosing was carried out through a sparging method (materials and methods section) to allow all $\mathrm{CO}_{2}$ to be consumed at the electrode and transformed into methane.

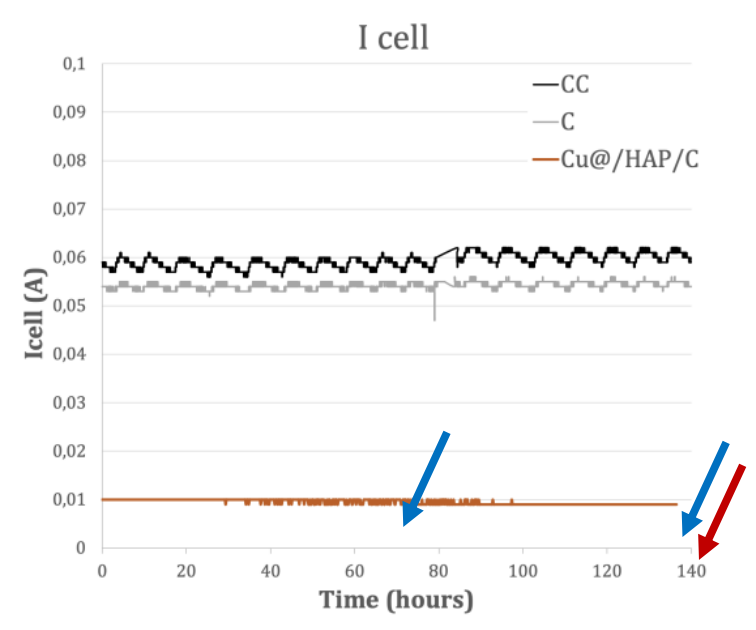

Fig. 6. Current circulating between the electrodes according to the material used. $\mathrm{CC}=$ carbon cloth; $\mathrm{C}=$ biochar.

As can be seen from the figure, the current produced is influenced by the type of material used as a cathode. An evident variability in the current output is noticed. Carbon cloth (CC) and biochar (C) exhibit higher currents than the multicomposite $\mathrm{Cu} @ / \mathrm{HAP} / \mathrm{C}$. These results are not surprising considering that with the same potential applied, the reisistivity of the multicomposite is higher due to the presence of HAP.

The moles of $\mathrm{H}_{2}$ that could ideally be produced by the system were also calculated, considering the charge supplied to be used exclusively for the $\mathrm{H}_{2}$ production reaction. Table 1 summarizes the results obtained in moles of $\mathrm{H}_{2}$ per day, averaging the currents as a function of the monitoring time.

Table 1. Ideal mmol of hydrogen produced daily by the polarization.

\begin{tabular}{|c|c|}
\hline material & $\mathbf{H}_{\mathbf{2}}(\mathbf{m m o l} / \mathbf{d})$ \\
\hline $\begin{array}{c}\text { Carbon Cloth } \\
(\mathrm{CC})\end{array}$ & 23 \\
\hline Biochar (C) & 23 \\
\hline $\begin{array}{c}\text { Multicomposite } \\
\mathrm{Cu} @ / \mathrm{HAP} / \mathrm{C}\end{array}$ & 4 \\
\hline
\end{tabular}

From the values obtained, the presence of the multicomposite catalyses the production of hydrogen at the electrode less easily, 6-times lower values of mmol produced per day.

The $\mathrm{pH}$ of the system varied according to the electrode used (as displayed by table 2 ) and it was expected to rise as a function of the hydrogen consumption due to the applied polarization. 
Table 2. Measurements of $\mathrm{pH}$ during the experiment

\begin{tabular}{|c|c|c|c|}
\hline material & \multicolumn{3}{|c|}{ pH } \\
\hline & Day 1 & Day 3 & Day 6 \\
\hline Carbon Cloth (CC) & 6.5 & 10 & 10 \\
\hline Biochar (C) & 6.5 & 10 & 10 \\
\hline $\begin{array}{c}\text { Multicomposite } \\
\text { Cu@/HAP/C }\end{array}$ & 6.5 & 6.5 & 7 \\
\hline
\end{tabular}

As can be seen, a correction of the $\mathrm{pH}$ was necessary $(0.1$ $\mathrm{M} \mathrm{HCl} \mathrm{each} \mathrm{time)} \mathrm{for} \mathrm{both} \mathrm{systems} \mathrm{using} \mathrm{carbon} \mathrm{cloth} \mathrm{and}$ biochar due to the uptake of hydrogen ions from the solution. However, this trend seems not to interest the multicomposite system in which the $\mathrm{pH}$ results more stable, maintaining optimal conditions for the inoculum to produce methane.

\subsubsection{Methane production}

The gaseous methane was detected as a volumetric percentage contained within the $1 \mathrm{~L}$ flex-foil gasbags. The values that emerged from gas chromatography refer exclusively to the methane produced during sampling, which lasted about 60 minutes, for each experiment conducted. Figure 7 shows the results obtained from the gas chromatographic analyses at the end of the experiment.

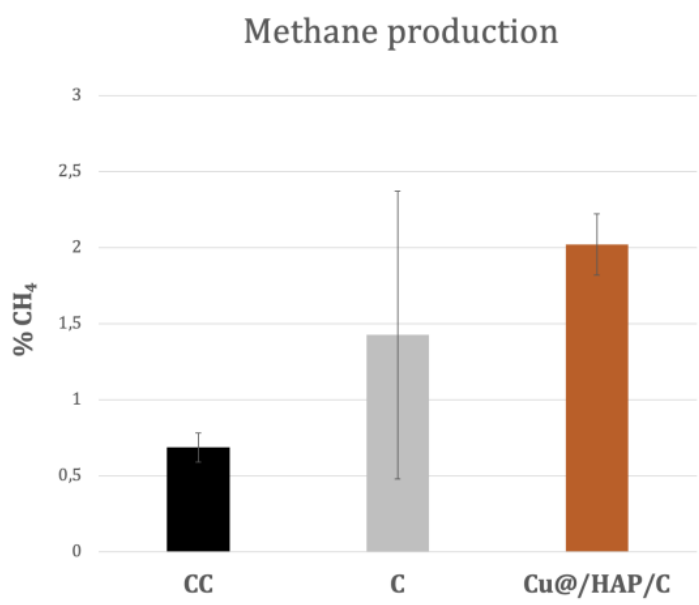

Fig. 7. $\mathrm{CH}_{4}$ produced at the end of the experiment. $\mathrm{CC}=$ carbon cloth; $\mathrm{C}=$ biochar.

At first glance, the material effect on experimentation can be seen, characterized in general by an upward trend in methane production, showing a higher production in the presence of biochar. These results are also very promising since the highest methane production was found for the $\mathrm{Cu} @ / \mathrm{HAP} / \mathrm{C}$, in spite the current generated on the electrode was the lower one, suggesting a selectivity for the direct reduction of $\mathrm{CO}_{2}$ into methane in presence of the inoculum.

\section{Conclusion}

Comparing the results from the electrochemical and analytical point of view it the better performances of the Multicomposite $\mathrm{Cu} @ / \mathrm{HAP} / \mathrm{C}$ than the other materials tested (carbon cloth and biochar) point out in an evident way.

This suggests the use of a different metabolic pathway to produce methane, probably associated with a direct passage of the electron from the electrode to the methanogens, avoiding a dispersion of hydrogen into the solution. Over time, the cell currents and the differences between the different materials remain constant.

An excessive enhancement of the $\mathrm{pH}$ suddenly occurs in the case of carbon cloth and biochar, in a few days, while the Multicomposite $\mathrm{Cu} @ / \mathrm{HAP} / \mathrm{C}$ guarantee neutral values for longer time. The effect of $\mathrm{pH}$ stabilization can be adduced to the presence of HAP in the composite. This phenomenon, associated to the presence of $\mathrm{Cu}$ nanoparticle catalysts, can be responsible for the advantage in terms of the methane production process.

\section{References}

1. N. Aryal, T. Kvist, F. Amman, D. Pant, L. D. Ottosen, Biores. Technol., 264, (2018).

2. R. Blasco-Gomez, P. Batle-Vilanova, M. Villano, M. Balaguer, J. Colprin e S. Puig, Int J. Mol Sci, 18, 32, (2017).

3. P. Clauwaert, Water Sci. Technol., 57, (2008).

4. P. Clauwaert, W. Verstraete, Appl. Microbiol. Biotechnol., 82, (2009).

5. P. Beese-Vasbender, Bioelectrochem., 102, (2015).

6. R. K. Thauer, K. Jungermann e K. Decker, Bacteriol. Rev., 41, (1977).

7. J.-L. Garcia, B. Patel, B. Ollivier, 6, (2000).

8. Y. Liu, W. Whitman, Ann. N. Y. Acad. Sci., 1125, (2008).

9. M. Lever, Trends Microbiol., 24, 2, (2016).

10. F. Sousa, T. Thiergart, G. Landan, S. Nelson-Sathi, I. Pereira, J. Allen, N. Lane, W. Martin, Philos. Trans. R. Soc. B: Biol. Sci., 368, 1622, (2013).

11. S. Gajaraj, Y. Huang, P. Zheng, Z. Hu, Biochem. Eng. J., 117, (2017).

12. Q. Fu, Y. Kuramochi, N. Fukushima, H. Maeda, K. Sato, H. Kobayashi, Environ. Sci. Technol., 49, (2015).

13. D. E. A. Park, Appl. Environ. Microbiol., 65, (1999).

14. D. Liu, L. Zhang, S. Chen, C. Buisman A. ter Heijne, Water Res., 99, (2016).

15. Y. Dang, D. Holmes, Z. Zhao, T. Woodard, Y. Zhang, D. Sun, L.-Y. Wang, K. Nevin, D. Lovley, Bioresour. Technol., 220, (2016).

16. X. Guo, J. Liu, B. Xiao, Int. J. Hydr. En., 38, (2013). 
17. M. Siegert, M. Yates, A. Spormann, B. Logan, ACS Sustain. Chem. Eng., 3, 2015.

18. A. Schievano, A. Goglio, C. Erckert, S. Marzorati, L. Rago, P. Cristiani, Detritus, 1 (2018)

19. S. Marzorati, A. Goglio, S. Fest-Santini D. Mombelli, F. Villa, P. Cristiani, A. Schievano, Int. J Hydr. En. 44 (2019)

20. C. Cruz Viggi, S. Simonetti, E. Palma, P. Pagliaccia, C. Braguglia, S. Fazi, S. Baronti, M. Navarra, I. Pettiti, C. Koch, F. Harnisch, F. Aulenta, Biotechnol. Biofuels 10, (2017).

21. J. Mumme, F. Srocke, K. Heeg, M. Werner, Bioresour. Technol., 164, (2014).

22. A. Rendón-Calle, S. Builes, F. Calle-Vallejo, Curr. Opin. Electrochem., 9, (2018)

23. R. Chong, Y. Fan, Y. Du, L. Liu, Z. Chang, D. Li, Int. J. Hydr. En., 3 (2018)

24. P. Cristiani, A. Goglio, S. Marzorati, S. Fest-Santini, A. Schievano, Front. En. Res. 8 (2020)

25. M. Ferri, S. Campisi, L. Polito, J. Shen, A. Gervasini, J. Hazard. Mater., 2021, doi: 10.1016/j.jhazmat.2021.126656

26. P.R. Yaashika, P. Senthil Kumar, Sunita Varjani, A. Saravanan, Biotechnol. Reports, 28, (2020) 